\title{
Bir Kaya Şevinin Devrilme Türü Duraysızlık Açısından Kinematik ve Sayısal Analizlerle Değerlendirilmesi (Devgeriş, Samsun)
}

Assessment of A Rock Slope in Terms of Toppling Failure by Kinematic and Numerical Analyses (Devgeriş, Samsun)

\section{Ayberk KAYA}

Recep Tayyip Erdoğan Üniversitesi, Mühendislik Fakültesi, Jeoloji Mühendisliği Bölümü, RİZE

$\begin{array}{lll}\text { Geliş (received) } & : & 25 \text { Ocak (January) } 2016 \\ \text { Düzeltme (revised) } & : & 22 \text { Mart (March) } 2016 \\ \text { Kabul (accepted) } & : & 13 \text { Nisan (April) } 2016\end{array}$

ÖZ

Devrilme, yamaç içine doğru eğimli, birbirine paralel ve dike yakın süreksizlikler içeren kaya kütlerinde açılmış şevlerde gözlenen bir yenilme türüdür. Karadeniz Sahil Yolu'nun Devgeriş (Samsun) Mahallesi kesimindeki Eosen yaşlı tüflerde açılmış kaya şevi, süreksizlik kontrollü bir yenilmeye maruz kalma riski altındadır. Bu kaya şevinin kuzeybatı sınırından itibaren açılmış taşocağından malzeme alımı neticesinde şev içine doğru eğimli olan J2 nolu (245/80) eklem seti boyunca açılmalar meydana gelmiştir. $\mathrm{Bu}$ nedenle, kaya şevinde eklemlere bağlı olan bir yenilmenin gerçekleşme durumunu araştırmak için kinematik analizlerden ve sonlu elemanlar (FEM) tabanlı sayısal duraylılık analizlerinden yararlanılmıştır. Yapılan kinematik analizler, J2 nolu eklemler boyunca devrilme olasılığının olduğunu göstermektedir. Devrilme olasılığı sayısal analizlerle incelendiğinde güvenlik sayısının en kötü koşullar için 0.86, mevcut koşullar için 1.23 olduğu ve devrilme türü bir yenilmenin gerçekleşebileceği belirlenmiştir. Kaya şevi, bulonlarla desteklendiğinde veya yatıklaştırıldığında duraysızlık sorunu ortadan kalkmaktadır.

Anahtar Kelimeler: Destek Tasarımı, Devrilme, Kaya Şevi, Kinematik Analiz, Sonlu Elemanlar Yöntemi, Şev Duraylılı̆̆ 1 .

\section{ABSTRACT}

Toppling is a failure mode observed in rock slopes with parallel and almost vertical discontinuities which are inclined into the hill. The rock slope excavated in Eocene aged tuffs, is located in the Devgeris (Samsun) district of Black Sea coast highway, and exposed to discontinuity-controlled failures. As a result of the quarry operation at the northwest side of studied rock slope, some cracks occurred along

A.Kaya

E-posta:ayberk.kaya@erdogan.edu.tr 
Kaya

the direction of J2 (245/80) joint set. Therefore, the kinematic and FEM-based numerical analyses were carried out in order to investigate the possibility of discontinuity-controlled failures. The results of the kinematic analyses showed that toppling failure is possible along the J2 joint set. It was determined that the factor of safety value is 0.86 for the worst condition and 1.23 for current condition when possibility of toppling failure is investigated by numerical analyses. After bolting or slope flattening, the rock slope becomes stable.

Key Words: Support Design, Toppling, Rock Slope, Kinematic Analysis, Finite Element Method, Slope Stability.

\section{GİRIŞ}

Türkiye'de kütle hareketlerinin en çok gözlendiği bölge Doğu Karadeniz Bölgesi'dir. Bölgenin topoğrafik ve jeolojik yapısı, yağışların bol olması ve buna bağlı olarak kayaçların ayrışması, potansiyel heyelan alanlarını oluşturmaktadır. Son yıllarda hızlı nüfus artışına bağlı olarak bu alanlarda yeni yerleşim yerleri için büyük hacimli kazıların yapılması veya plansız açık ocak işletmeciliği, pek çok kütle hareketini tetiklemiştir ve tetiklemeye devam etmektedir. Meydana gelen bu duraysızlıklar, hem ekonomik kayıplara hem de can kayıplarına yol açmaktadır. Kaya şevlerinde meydana gelen yenilmeler ise genellikle kütle içindeki süreksizliklere bağlı olarak gelişmektedir. Kazı aşamasında bu tür duraysızlık sorunlarıyla karşılaşmamak için şevlerin duraylılığı, tasarım aşamasında uygun analiz yöntemleriyle araştırılmalıdır.

Samsun İli’nin Devgeriş Mahallesi'ndeki çalışma alanı (Şekil 1), şehir merkezinden yaklaşık 3 km uzaklıkta olup, Karadeniz Sahil Yolu'nun hemen bitişiğindeki 2008 yılında basamaklandırılmış kaya şevini kapsamaktadır. Bu kaya şevinin kuzeybatı sınırından itibaren 6 yıl süre ile hidrolik kırıcı kullanılarak açık ocak işletmeciliği yapılmış ve düzensiz geometriye sahip bir alan meydana getirilmiştir (Şekil 2). Bu faaliyet sonucunda taşocağı sınırından itibaren kaya şevini kesen süreksizler boyunca açılmalar meydana gelmiştir. $\mathrm{Bu}$ amaçla, Eosen yaşlı tüflerde açılmış bu şevin duraylılığını araştırmak için ayrıntılı mühendislik jeolojisi çalışmaları gerçekleştirilmiştir. Yapılan çalışmalar arazi, laboratuvar ve duraylılık analiz çalışmaları olmak üzere üç aşamada yürütülmüştür. Arazi çalışmaları kapsamında jeoloji haritası hazırlanmış, eklemlerin özelliklerini belirlemek için hat etütleri yapılmış ve laboratuvar deneylerinde kullanılmak üzere blok örnekler alınmıştır. Laboratuvar çalışmalarında tüflerin fiziko-mekanik ve elastik özelliklerini belirlemek için deneyler yapılmıştır. Şev duraylılık araştırmalarında ise kinematik ve sonlu elemanlar tabanlı sayısal analizlerden yararlanılmıştır.

\section{ÇALIŞMA ALANININ VE ÇEVRESININ JEOLOJISİ}

Çalışma alanı ve çevresinde, yaşlıdan gence doğru Geç Kretase yaşlı tortul kayaçlar, Eosen yaşlı volkanik ve tortul kayaçlar, MiyosenPliyosen yaşlı tortul kayaçlar ve Kuvaterner yaşlı alüvyonlar yüzeylenmektedir (Güven, 1993). 
İlk defa Barka vd. (1986) tarafindan tanımlanan Tekkeköy Formasyonu, KBGD doğrultusu boyunca çalışma alanında ve çevresinde geniş̧̧e bir alanda yüzeylenmektedir. Formasyon, tabanda ince tabakalı kumtaşı ve marn ile başlayıp üst seviyelere doğru kalın tabakalı tüflerle son bulmaktadır. Birim, yer yer bazalt daykları tarafından kesilmiştir. Çalışma alanında, formasyona ait, içinde eksfoliasyonların geliştiği açık yeşil renkli tüfler yüzeylenmektedir. Yer yer ince laminalı tüf seviyeleri de gözlenmektedir. Birim, sistematik ve gelişi güzel oluşmuş eklemler içermektedir. Eklem yüzeyleri orta derecede bozunmuş olup, bozunma rengi koyu kahve-sarı arasındadir. Birimin yaşı, Barka vd. (1986) tarafindan yapılan çalışmada Eosen olarak belirlenmiştir. Çalışma alanı ve çevresine ait jeoloji haritası Şekil 3’te verilmiştir.

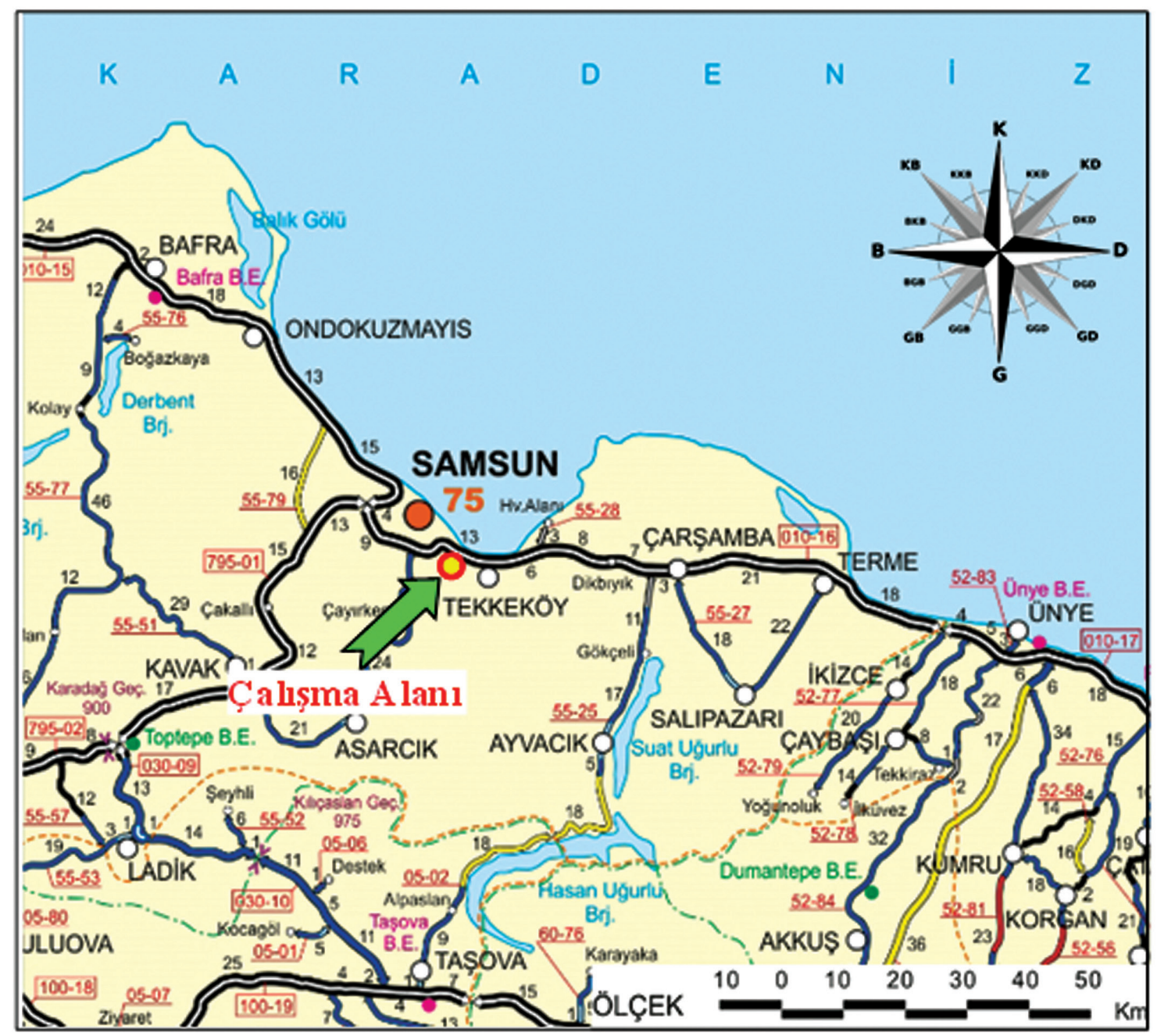

Şekil 1. Çalışma alanına ait yer bulduru haritası.

Figure 1. Location map of the study area. 
Kaya
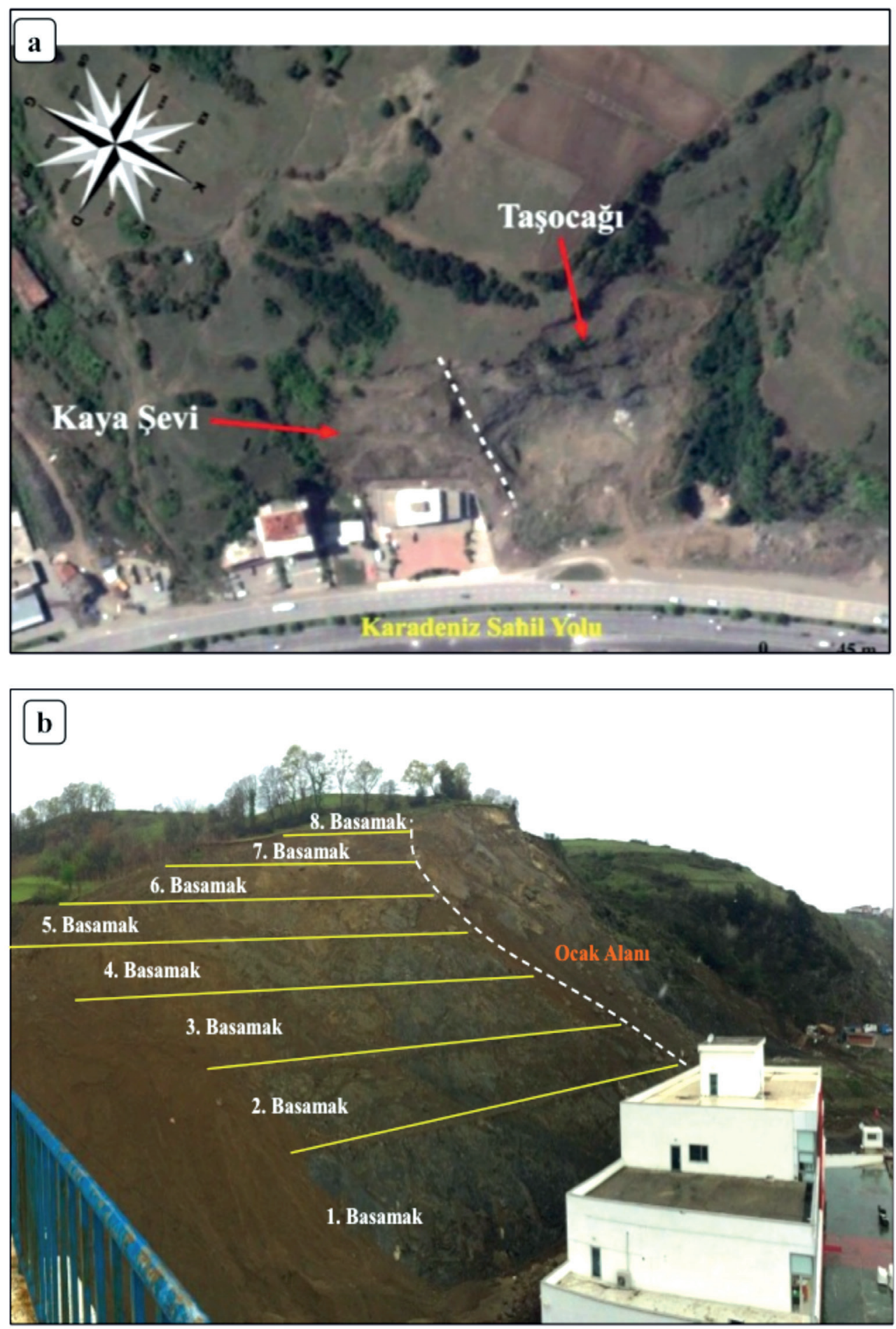

Şekil 2. Kaya şevinin ve taşocağının (a) hava fotoğrafındaki ve (b) arazideki görünümleri.

Figure 2. (a) Aerial and (b) field views of the studied rock slope and quarry. 


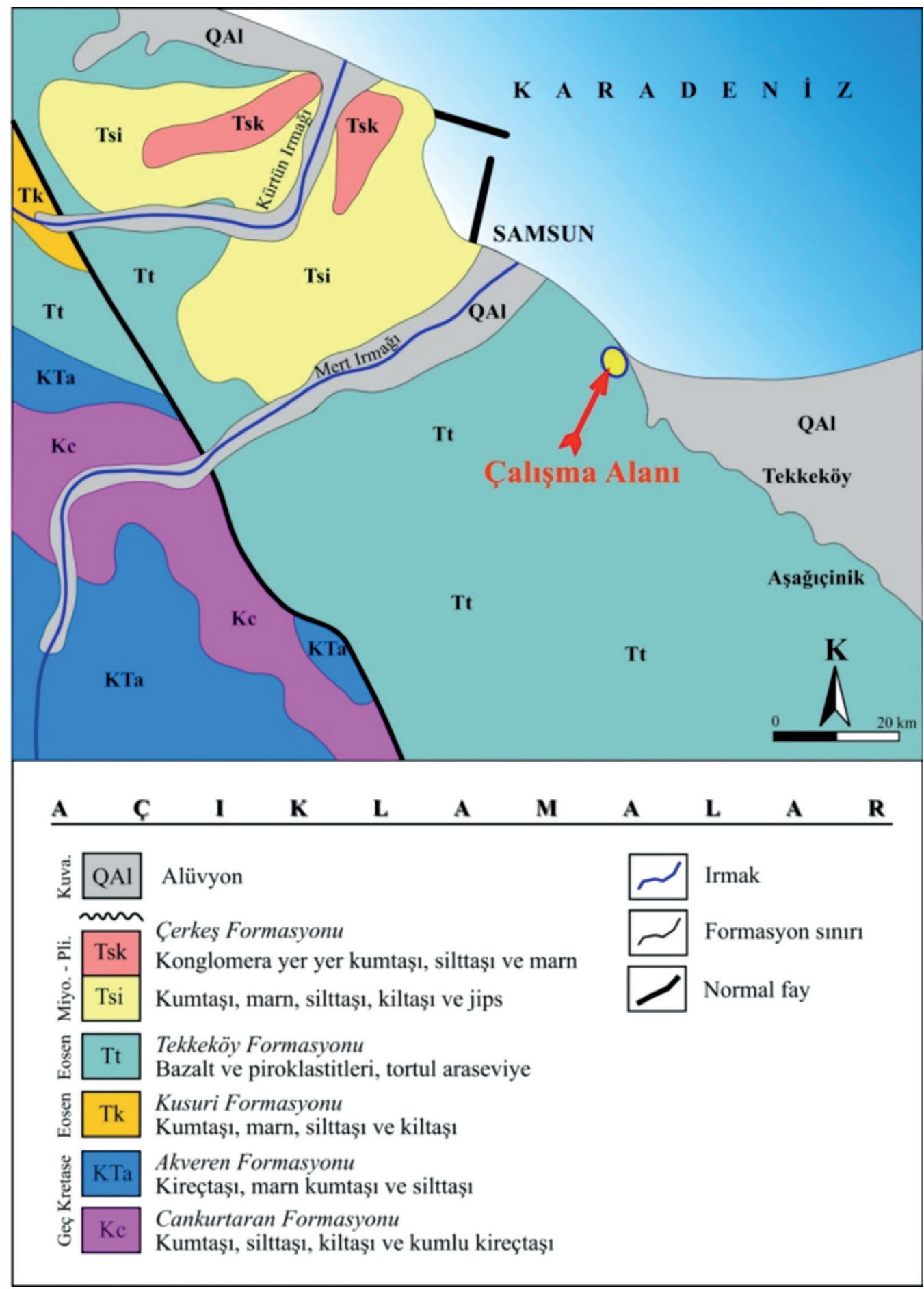

Şekil 3. Çalışma alanı ve yakın çevresine ait jeoloji haritası (Güven, 1993'ten değiştirilerek).

Figure 3. Geological map of the close vicinity of the study area (modified from Güven, 1993). 
Kaya

\section{TÜFLERIN FIZIKO-MEKANIK VE ELASTÍK ÖZELLIKKLERI}

Çalışma alanından alınan bloklardan laboratuvar ortamında silindirik numuneler hazırlanarak tüflerin fiziko-mekanik ve elastik özellikleri belirlenmiştir.

ISRM (2007) tarafından önerilen yöntemler esas alınarak tüflerin birim hacim ağırlığ 1 , nokta yükü dayanımindeksi, tek eksenli basınç dayanımı ve elastisite modülü değerleri saptanmıştır. Tüflerin taze ve eklem yüzeylerinden, ISRM (2007) tarafindan önerilen yöntemlere göre L-tipi Schmidt sertlik çekici kullanılarak geri tepme sayısı ölçümleri alınmıştır. Ölçümler düşey tutuş açısına göre yapıldığı için belirlenen değerlere herhangi bir düzeltme uygulanmamıştır.

Tüflerin birim hacim ağırlık $(\gamma)$, nokta yükü dayanım indeksi $\left(\mathrm{I}_{\mathrm{s}(50)}\right)$, tek eksenli basınç dayanımı $\left(\sigma_{\mathrm{ci}}\right)$, elastisite modülü $\left(\mathrm{E}_{\mathrm{i}}\right)$ ve Schmidt sertlik çekici geri tepme sayısı ( $R$ ve r) değerleri Çizelge 1'de özet olarak verilmiştir.
Eklemlerin özellikleri, ISRM (2007) tarafından önerilen ölçütlere göre tanımlanmıştır. Hat etüdü çalışmaları ile eklemlere ait yönelim, aralık, açıklık, devamlılık, yüzey pürüzlülüğü ve dalgalılığı, bozunma derecesi, dolgu malzemesinin özelliği ve yüzeylerindeki su durumu gibi özellikler tespit edilmiştir.

Pürüzlü özellikte olan eklem yüzeylerinin makaslama dayanımı parametreleri ise Barton ve Bandis (1990) tarafindan tavsiye edilen yenilme ölçütü kullanılarak belirlenmiştir. İlk önce CANMET (1977) tarafindan önerilen yönteme göre deformasyon kontrollü doğrudan makaslama deneyleri yapılmış ve tüflere ait temel sürtünme açısı $\left(\phi_{\mathrm{b}}\right) 30^{\circ}$ olarak belirlenmiştir (Şekil 4a). Kaya şevine etkiyen normal gerilme seviyesi, şevin yüksekliği $(65 \mathrm{~m})$ ile kayanın birim hacim ağırlığının (19.84 kN/m³) çarpılmasıyla $1.3 \mathrm{MPa}$ olarak hesaplanmıştır. Daha sonra da 0-1.3 MPa arasında değişen farklı normal gerilmeler $\left(\sigma_{\mathrm{n}}\right)$ için (1) ve (2) nolu eşitlikler yardımıyla kayma gerilmesi $(\tau)$ değerleri hesaplanmış ve elde edilen

Çizelge 1. Tüflere ait fiziko-mekanik ve elastik özellikler.

Table 1. Physico-mechanical and elastic properties of the tuffs.

\begin{tabular}{lccccc}
\hline \multicolumn{1}{c}{ Özellikler } & $\begin{array}{c}\text { Örnek } \\
\text { Sayıs1 }\end{array}$ & Ortalama & $\begin{array}{c}\text { En } \\
\text { Büyük }\end{array}$ & $\begin{array}{c}\text { En } \\
\text { Küçük }\end{array}$ & Std. Sp. \\
\hline Birim hacim ağırlık $\left(\mathrm{g}, \mathrm{kN} / \mathrm{m}^{3}\right)$ & 18 & 19.84 & 21.46 & 18.71 & 2.14 \\
\hline Nokta yükü dayanım indeksi $\left(\mathrm{I}_{\mathrm{s}(50)}, \mathrm{MPa}\right)$ & 42 & 4.10 & 6.71 & 2.84 & 2.02 \\
\hline Tek eksenli basınç dayanımı $\left(\sigma_{\mathrm{c}}, \mathrm{MPa}\right)$ & 15 & 20.52 & 34.41 & 14.16 & 6.13 \\
\hline Elastisite modülü $\left(\mathrm{E}_{\mathrm{i}}, \mathrm{GPa}\right)$ & 5 & 5.4 & 7.3 & 5.7 & 2.4 \\
\hline
\end{tabular}

$\begin{array}{ll}\text { Schmidt sertlik çekici geri tepme sayısı* } & \text { R: } 36, \text { r: } 26\end{array}$

*R-taze yüzey, r-eklem yüzeyi

\section{EKLEMLERIN ÖZELLİKLERİ}

Çalışma alanındaki tüflerin içerdiği eklemlerin özelliklerini belirlemek için kaya şevindeki basamak aynalarında yapılan hat etüdü çalışmalarından yararlanılmıştır. $\sigma_{\mathrm{n}}-\tau$ veri çiftleri kullanılarak doğrusal olmayan yenilme zarfı çizilmiştir. Bu yenilme zarfına çizilen teğetten pürüzlü eklem yüzeylerinin sürtünme açısı $(\phi)$ ve kohezyon (c) değerleri belirlenmiştir (Şekil 4b). 
$\phi_{r}=\left(\phi_{b}-20\right)+20(r / R)$

$\tau=\sigma_{n} \tan \phi_{r}+J R C \log \frac{J C S}{\sigma_{n}}$

Burada;

$\tau$ : kayma gerilmesi (MPa)

$\sigma_{\mathrm{n}}$ : eklem düzlemine etki eden normal gerilme (MPa)

JRC: eklem yüzeyi pürüzlülük katsayısı

JCS: eklem yüzeyinin dayanımı (MPa)

$\phi_{\mathrm{r}}$ : artık sürtünme açısı

$\phi_{\mathrm{b}}$ : pürüzsüz ve düz yüzeye ait temel sürtünme açıs1

R: taze yüzeyin Schmidt çekici geri tepme sayısı ve

r: eklem yüzeyinin Schmidt çekici geri tepme sayısidır.
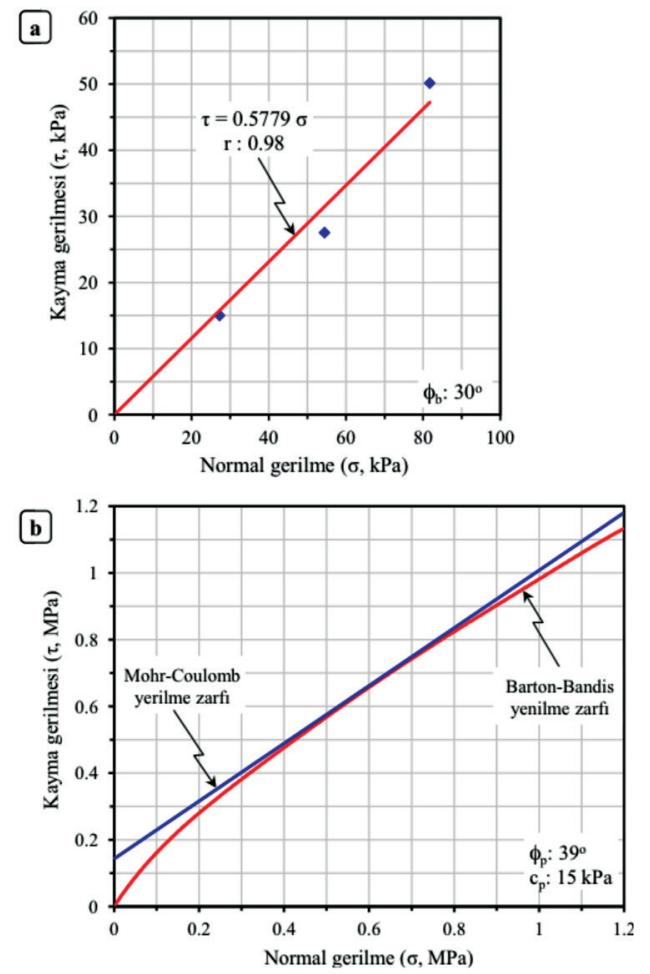

Şekil 4. (a) Pürüzsüz yüzeye ait $\phi_{\mathrm{b}}$ değeri ile (b) eklem yüzeylerine ait $\phi$ ve $\mathrm{c}$ değerlerini belirlemek için çizilen $\sigma-\tau$ grafikleri.

Figure 4. $\sigma-\tau$ graphs in order to determine (a) $\phi_{b}$ value of the smooth surface and (b) $\phi$ and $c$ values of the joint surfaces.
Kaya kalite göstergesi (RQD), Priest ve Hudson (1976) tarafından önerilen (3) nolu eşitlikten; hacimsel eklem sayısı $\left(\mathrm{J}_{\mathrm{v}}\right)$ ise Palmström (2005) tarafindan tavsiye edilen (4) nolu eşitlik yardımıyla hesaplanmıştır.

$R Q D=100 e^{-0.1 \lambda}(0.1 \lambda+1$

$J_{v}=\frac{110-R Q D}{2.5}$

Burada;

$\lambda$ : 1 metre uzunluğundaki ölçüm hattını kesen eklem sayısı ve

$\mathrm{J}_{\mathrm{v}}: 1 \mathrm{~m}^{3}$ lük kaya bloğundaki eklem sayısıdır.

ISRM (2007) tarafından önerilen tanımlama ölçütlerine göre değerlendirilen eklemlerin özellikleri ile literatürde tanımlanan yöntemlere göre belirlenen eklem sıklığı $(\lambda)$, kaya kalite göstergesi (RQD), hacimsel eklem sayısı $\left(\mathrm{J}_{\mathrm{v}}\right)$, sürtünme açısı $(\phi)$ ve kohezyon (c) değerleri Çizelge 2'de özet olarak sunulmuştur.

\section{TÜFLERINN KAYA KÜTLESİ ÖZELLIKKLERİ}

Tüflerden oluşankayakütlesine aittek eksenli basınç dayanımı ve kaya kütle sabitleri Hoek vd. (2002) tarafından önerilen eşitlikler yardımıyla; deformasyon modülü ise Hoek ve Diederichs (2006) tarafindan önerilen eşitlik kullanılarak belirlenmiştir. Poisson oranı hesaplanırken Aydan vd. (1993) tarafından önerilen ampirik eşitlikten yararlanılmıştır. Jeolojik Dayanım İndeksi (GSI) değerini saptamak için Hoek vd. (2013) tarafından önerilen denklem kullanılmış ve GSI değeri 46 olarak belirlenmiştir. Ayrıca, 
Kaya

RocLab v1.0 (Rocscience, 2002) programından yararlanılarak tüfler için kaya malzemesi sabiti $\left(\mathrm{m}_{\mathrm{i}}\right) 13$ olarak, şev kazısı sırasında mekanik

Çizelge 2. Tüflerdeki eklemlere ait özellikler.

Table 2. Properties of joints in the tuffs. kazı uygulandığı için örselenme faktörü (D) 0.7 olarak kabul edilmiştir.

\begin{tabular}{|c|c|}
\hline Özellik & Değer \\
\hline Eklem takımları & $\begin{array}{l}\text { JI: } 320 / 60(\text { Set } 1) \\
\text { J2: } 245 / 80(\text { Set } 2) \\
\text { J3: } 080 / 60(\text { Set } 3)\end{array}$ \\
\hline Eklem aralığ $1(\mathrm{~cm})$ & $6.7 *$ \\
\hline Tanımlama (ISRM, 2007) & Yakın aralıklı \\
\hline Eklem açıklığı (mm) & $1.5^{*}$ \\
\hline Tanımlama (ISRM, 2007) & Açık \\
\hline Eklem devamlılığ $1(\mathrm{~m})$ & $10.5^{*}$ \\
\hline Tanımlama (ISRM, 2007) & Yüksek devamlı \\
\hline Eklem yüzeyi pürüzlülüğü (JRC) & $14-16$ \\
\hline Tanımlama (ISRM, 2007) & Dalgalı pürüzlü \\
\hline Eklemlerdeki dolgu malzemesinin özelliği & $\begin{array}{l}\text { Çok ince kil sıvaması } \\
\text { yer yer }<2 \mathrm{~mm} \text { kalsit dolgu }\end{array}$ \\
\hline Eklem yüzeylerinin bozunma derecesi (ISRM, 2007) & Orta derecede bozunmuş \\
\hline Eklem yüzeylerindeki su durumu (ISRM, 2007) & Kuru ve sızıntı yok \\
\hline Eklem siklığ $1\left(1, \mathrm{~m}^{-1}\right)$ & $15^{*}$ \\
\hline Tanımlama (Franklin vd., 1971) & Çok çatlaklı- kırıklı \\
\hline $\begin{array}{l}\text { Hacimsel eklem sayısı } \\
\left(\mathrm{J} v, \text { eklem } / \mathrm{m}^{3}\right)\end{array}$ & 22 \\
\hline Tanımlama (ISRM, 2007) & Çok küçük bloklar \\
\hline Kaya kalite göstergesi (RQD, \%) & 55.7 \\
\hline Tanımlama (Deere, 1964) & Orta \\
\hline Sürtünme açısı $\left(\varphi,{ }^{\circ}\right)$ & 39 \\
\hline Kohezyon (c, kPa) & 15 \\
\hline
\end{tabular}

* Ortalama değer

Sayısal duraylılık analizlerinde kullanılmak amaciyla belirlenen Poisson oran $1 \quad\left(v_{m}\right)$, deformasyon modülü $\left(\mathrm{E}_{\mathrm{m}}\right)$, tek eksenli basınç dayanımı $\left(\sigma_{\mathrm{cm}}\right)$, kaya kütle sabitleri $\left(\mathrm{m}_{\mathrm{b}}, \mathrm{s}, \mathrm{a}\right)$ ve hesaplamalarda kullanılan eşitlikler Çizelge 3'te verilmiştir. 


\section{DURAYLILIK ANALIZLERI}

$\mathrm{Bu}$ çalışmada, tüflerde açılan kaya şevinin duraylılığ1 kinematik ve sayısal analizler yapılarak incelenmiştir. Duraylılık analizleri iki aşamada gerçekleştirilmiştir. İlk aşamada, kaya şevindeki yenilmelerin eklemler tarafindan kontrol edildiği varsayılarak potansiyel yenilme türlerini (düzlemsel ve kama tipi kayma, devrilme) ortaya koymak amaciyla kinematik analizler yapılmıştır. Kinematik analizlerde girdi parametresi olarak ana eklem takımlarının ve kaya şevinin yönelimleri ile eklem yüzeylerine ait sürtünme açısı değeri ( $\left.\varphi: 39^{\circ}\right)$ kullanılmıştır.
Çalışmada, Hoek ve Bray (1981) tarafından önerilen kinematik analiz yönteminden yararlanılmıştır. Sekiz adet basamaktan oluşan 070/48 yönelimli kaya şevi için yapılan kinematik analizler sonucunda J2 nolu (245/80) eklem setinin devrilme türü bir yenilme oluşturma olasılığının olduğu belirlenmiştir (Şekil 5). Taşocağı ile kaya şevi sınırındaki 6 . ve 7 . basamaklarda gözlenen açılmalar, devrilme riski taşıyan J2 nolu eklemlerin doğrultusu boyunca gelişmiştir (Şekil 6). Arazideki bu durum kinematik analiz sonuçlarıyla da uyumluluk göstermektedir.

Çizelge 3. Tüflere ait kaya kütle özellikleri ve hesaplamalarda kullanılan eşitlikler.

Table 3. Rock mass properties of the tuffs, and equations used in the calculations.

\begin{tabular}{llll}
\hline Literatür & Eşitlik & Not & Değerler \\
\hline Hoek vd. (2013) & $G S I=1.5$ JCond $_{89}+R Q D / 2$ & JCond $_{89}: 12$ & 46 \\
\hline
\end{tabular}

Aydan vd. (1993)

$$
v_{m}=0.25\left(1+e^{-\sigma_{c m} / 4}\right)
$$

Hoek ve Diederichs (2006)

$$
E_{m}=E_{i} \quad 0.02+\frac{1-(D / 2)}{1+e^{(60+15 D-G S I) / 11}}
$$

$\mathrm{GPa}$

$$
\sigma_{c m}=\sigma_{c i} \cdot \frac{\left(m_{b}+4 s-a\left(m_{b}-8 s\right)\right)\left(m_{b} / 4+s\right)^{a-1}}{2(1+a)(2+a)} \mathrm{MPa}
$$

$\begin{array}{ll}m_{b}=m_{i} e^{\frac{G S I-100}{28-14 D}} & m_{i}: 13 \\ D: 0.7\end{array}$

Hoek vd. (2002)

$s=e^{\frac{G S I-100}{9-3 D}} \quad 0.0004$

$$
a=\frac{1}{2}+\frac{1}{6}\left(e^{-G S I / 15}-e^{-20 / 3}\right)
$$

JCond $_{89}$ : Eklem durumu puanı, Bieniawski (1989) tarafından tanımlanmıştır 
Kaya

Son aşamada ise incelenen kaya şevindeki eklem kontrollü kayma riski, hem kaya kütlesinin deformasyon ve kütle özelliklerinin hem de eklemlerin makaslama dayanımının göz önüne alındığı sonlu elemanlar (FEM) tabanl1 Phase ${ }^{2}$ v8.0 (Rocscience, 2011) program1 kullanılarak incelenmiştir. Oluşturulan üç düğüm noktalı üçgen sonlu elemanlar modelinde HoekBrown yenilme ölçütü kullanılarak gerilmedeformasyon analizleri yapılmış ve yenilme türleri incelenmiştir. Sayısal analizlerde şevin mevcut koşullardaki duraylılık durumunun yanı sıra en kötü koşullardaki duraylılık durumu da incelenmiştir. En kötü koşullardaki duraylılık durumu incelenirken, eklemlerin suyla dolu olduğu varsayılmış ve sismik yükler dikkate alınmıştır. Ulusay vd. (2004) tarafından önerilen deprem azalım ilişkisi yardımıyla en büyük yatay yer ivmesi, $0.17 \mathrm{~g}$ olarak hesaplanmış ve sismik yük olarak modele eklenmiştir. Hesaplamalarda, çalışma alanına yaklaşık $20 \mathrm{~km}$ uzaklıkta bulunan ve son y1llarda sismik hareketlilik açısından aktif olan Karadeniz Fayı dikkate alınmıştır. Bu çalışmada, kaya şevinin duraylılık durumu için yeterli güvenlik sayısı değeri, 1.3 olarak seçilmiştir (Mines Branch, 1972). Analizlerde kullanılan değişkenler Çizelge 1-3’te sunulmuştur. Şevin geometrisi sekiz basamaklı kazı düzenine göre oluşturulmuştur (Şekil 7).

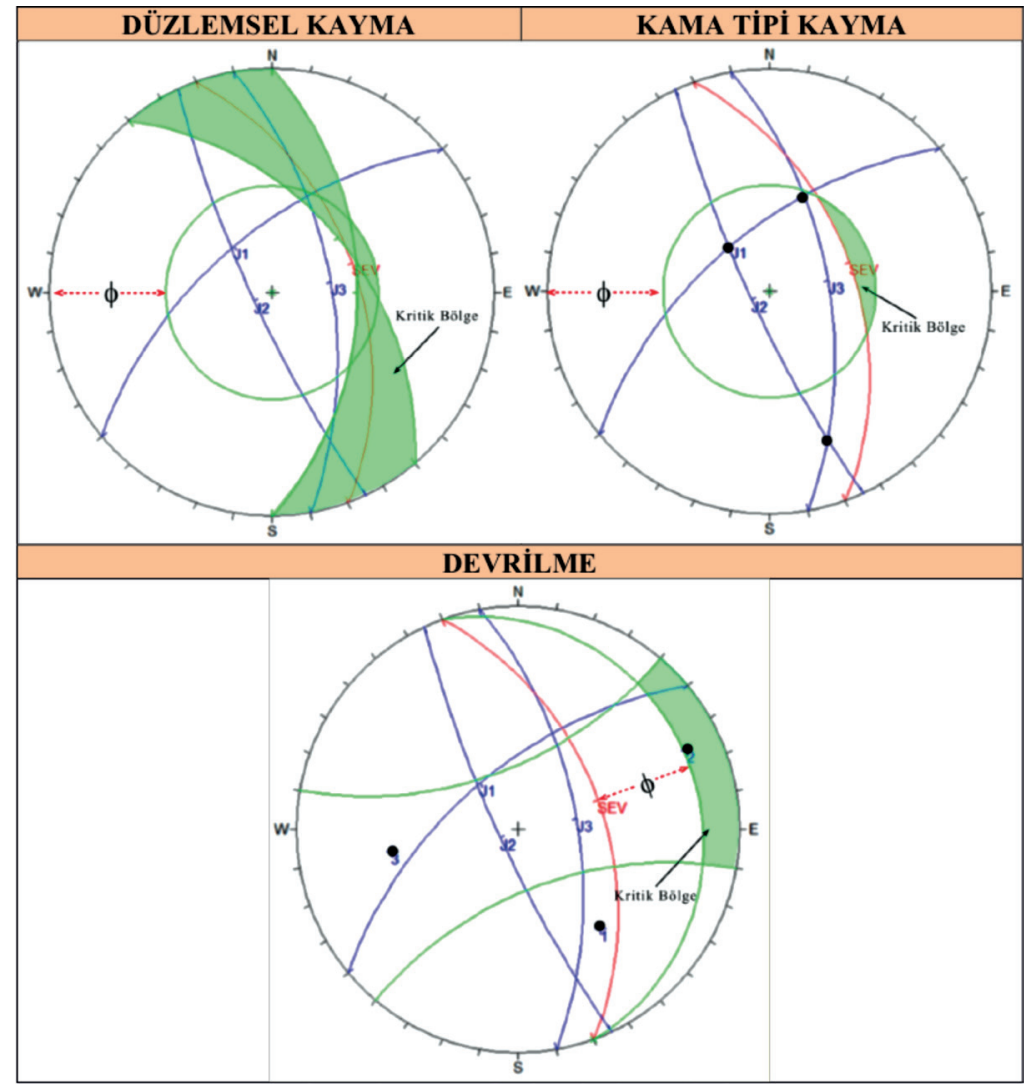

Şekil 5. Kaya şevi için düzlemsel kayma, kama tipi kayma ve devrilmenin kinematik analizi. Figure 5. Kinematic analyses of planar sliding, wedge sliding and toppling for the rock slope. 


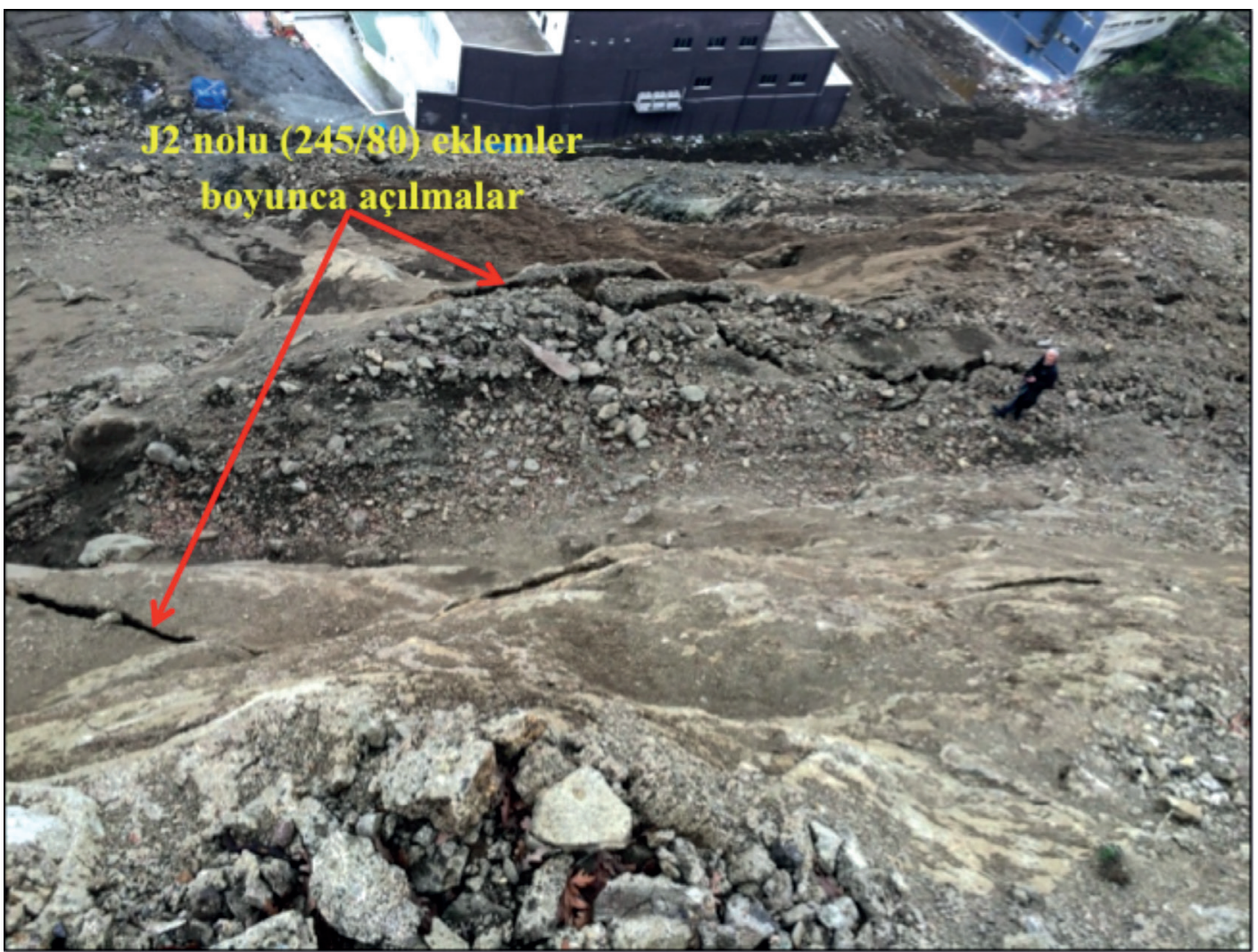

Şekil 6. Kaya şevindeki J2 nolu (245/80) eklemler boyunca açılmaları gösteren fotoğraf.

Figure 6. The photograph showing cracks developed along the J2 joint plane (245/80) at the rock slope.

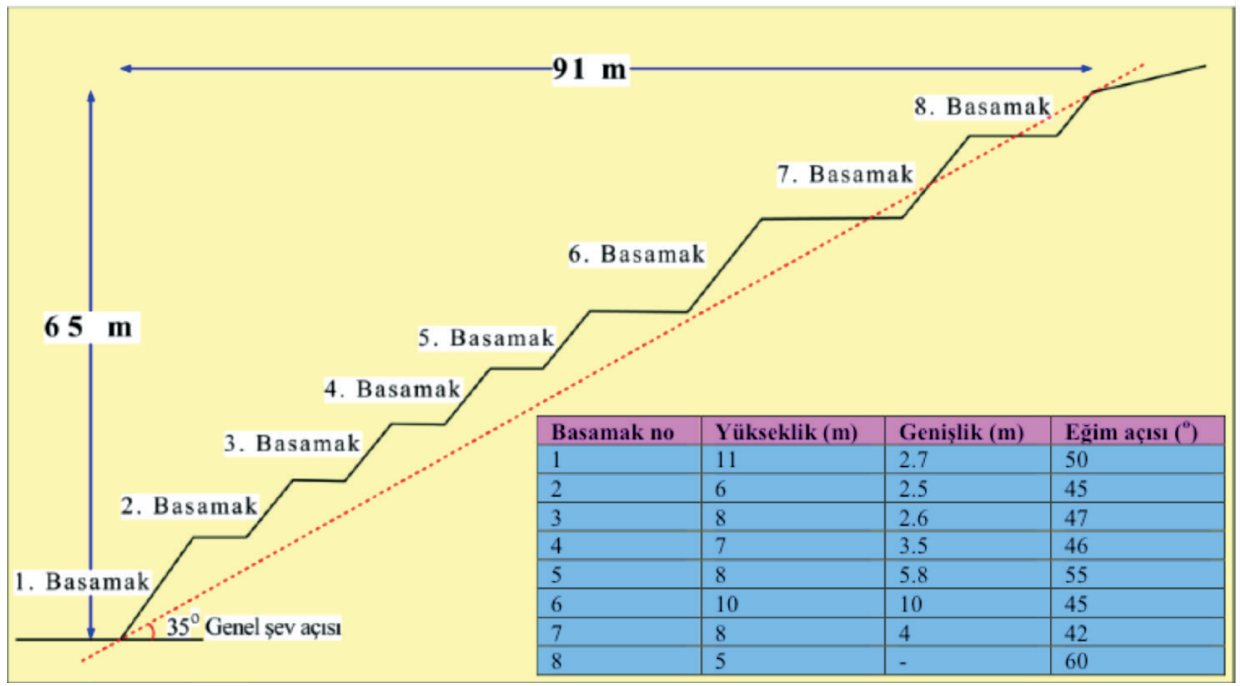

Şekil 7. Çalışma alanındaki kaya şevinin geometrisini gösteren kesit.

Figure 7. Cross-section showing the geometry of the rock slope in the study area. 
Kaya

Yapılan sayısal duraylılık analizleri sonucunda kaya şevine ait güvenlik sayısının en kötü koşullar için 0.86 (Şekil 8a); mevcut koşullar için ise 1.23 (Şekil 8b) olduğu ve devrilme riski taşıdığı saptanmıştır. Şekil 8c'de, yenilmelerin J2 nolu eklemler boyunca basamakların üst bölümünde geliştiği ve derinlere doğru eğilme deformasyonu şeklini alarak yamaç aşağ 1 doğru hareket ettiği görülmektedir. Dolayısıyla, olası yenilme probleminin önlenmesi için kaya şevinin desteklenmesi veya yeniden basamaklandırılması gerekmektedir.

Kaya şevini duraylı hale getirecek en uygun yöntemi belirlemek için Phase $^{2}$ v8.0 programından yararlanılmış ve yapılan sayısal analizler iki aşamada gerçekleştirilmiştir. İlk aşamada, mevcut şev geometrisi dikkate alınarak sistematik bulonlama uygulaması yapılmıştır. Duraylılık için kabul edilen güvenlik sayısını (F: 1.3) sağlayacak optimum bulon tasarımını belirlemek amaciyla farklı aralıklarda ve uzunluklarda Ø28 mm çaplı SN tip kaya bulonları kullanılmış ve performansları test edilmiştir. Sonuç olarak, kaya şevinin ikinci, üçüncü, dördüncü ve beşinci basamakları $2.0 \times 2.0 \mathrm{~m}$ aralığında ve $6 \mathrm{~m}$ uzunluğunda; açılmaların gözlendiği altıncı, yedinci ve sekizinci basamakların ise $2.0 \times 2.0 \mathrm{~m}$ aralığında ve $10 \mathrm{~m}$ uzunluğunda bulonlarla desteklenmesi halinde güvenlik sayısının 1.24'ten 1.33'e çıktığ 1 belirlenmiştir (Şekil 9a).

İkici aşamada ise $\mathrm{J} 2$ nolu eklemler boyunca açılmaların gözlemlendiği kütleyi ortadan kaldırmak için altıncı basamağın topuğundan itibaren farklı açılarda ve yüksekliklerde şev kazıları uygulanmış ve duraylılık için kabul edilen güvenlik sayısını sağlayan optimum basamak geometrisi belirlenmiştir. Kaya şevinin üst zonu, $30^{\circ}$ eğiminde, $12 \mathrm{~m}$ yüksekliğinde ve $5 \mathrm{~m}$ genişliğinde üç basamak olarak yatıklaştırıldığında güvenlik sayısının 1.42 olduğu saptanmıştır (Şekil 9b).

\section{SONUÇLAR VE ÖNERILER}

Bu çalışmada, Karadeniz Sahil Yolu'nun Devgeriş (Samsun) mahallesi kesimindeki Eosen yaşlı tüflerde açılmış kaya şevinin duraylılığı, kinematik ve sayısal analizler yapılarak araştırılmış ve elde edilen sonuçlar aşağıda maddeler halinde sunulmuştur:

a) Yapılan kinematik analizler sonucunda kaya şevindeki J2 nolu (245/80) eklem setinin, devrilme türü bir yenilme oluşturma olasılığının olduğu belirlenmiştir. Taşocağı ile kaya şevi sınırındaki 6. ve 7. basamaklarda, J2 nolu eklemlerin doğrultusu boyunca gelişmiş açılmalar, kinematik analiz sonuçlarının doğruluğunu kanıtlamaktadır.

b) Kaya şevinde J2 nolu (245/80) eklem setine bağlı bir yenilmenin gerçekleşme olasılı̆̆ı sonlu elemanlar (FEM) tabanlı sayısal analiz yöntemi ile incelendiğinde kaya şevi için güvenlik sayısı en kötü koşullar için 0.86 , mevcut koşullar için ise 1.23 olmaktadır. Bu değerler, duraylılık için kabul edilen F: 1.3 değerinden küçüktür. 


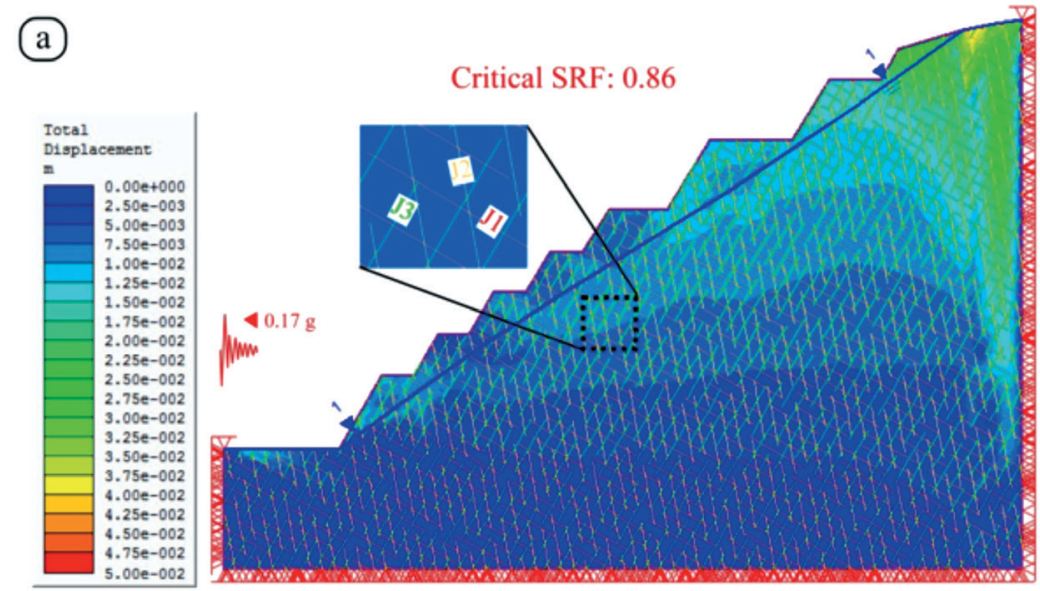

(b)

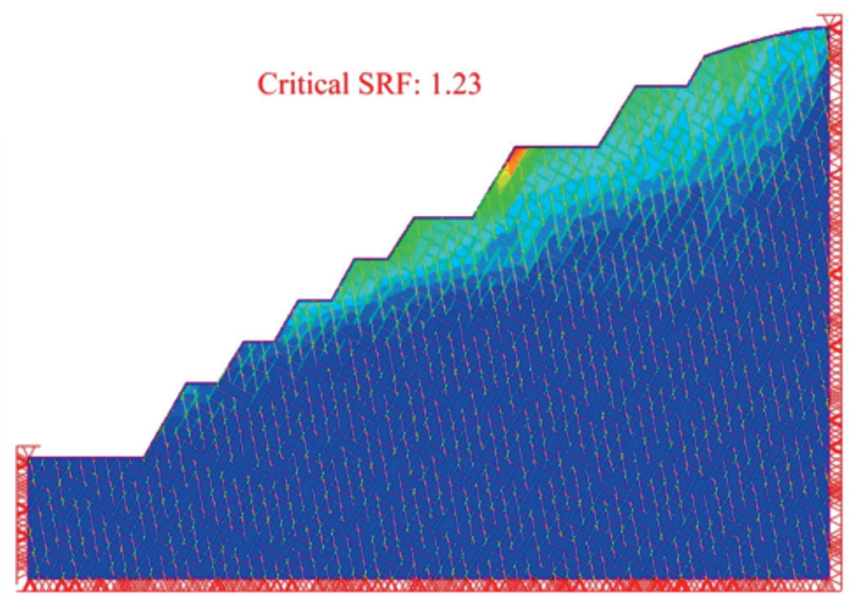

(c)
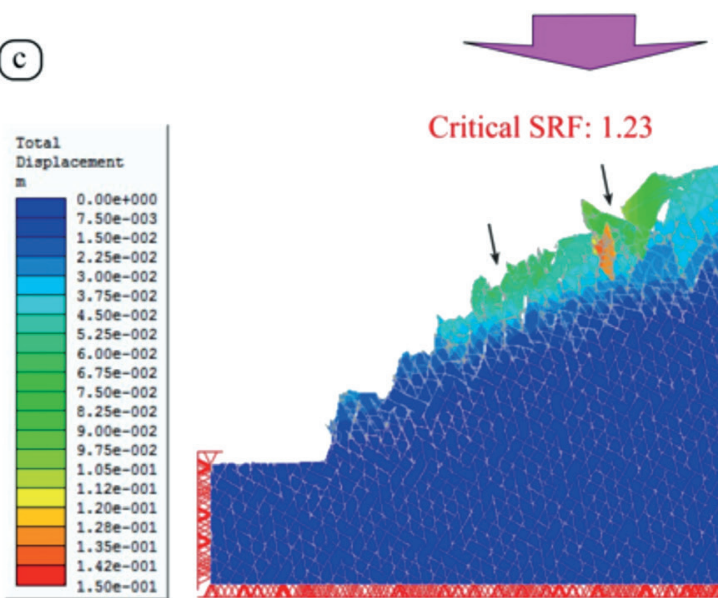

Critical SRF: 1.23

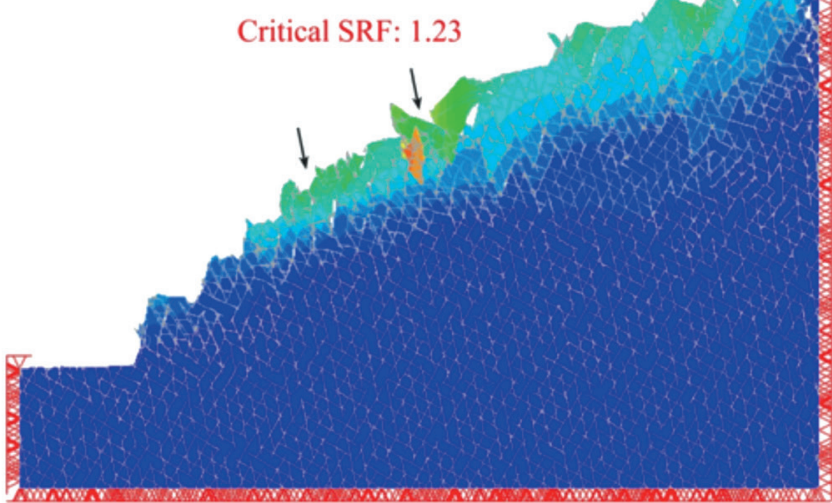

Şekil 8. Kaya şevinin yenilme öncesi (a) en kötü ve (b) mevcut koşullardaki durumu ile (c) yenilme sonrası durumunu gösteren sayısal analiz sonuçları.

Figure 8. Results of numerical analyses for the rock slope showing the pre-failure case (a) in worst, (b) current conditions, and (c) post-failure case. 
Kaya

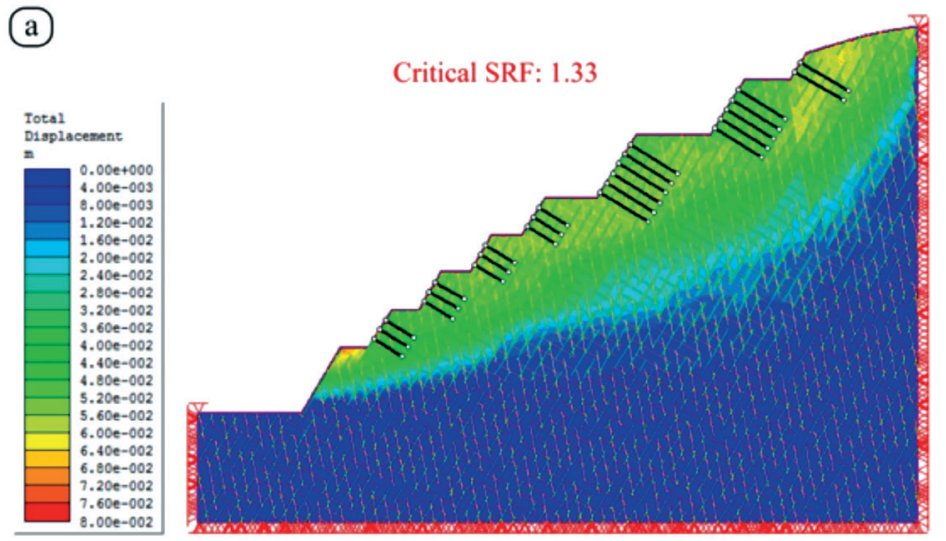

(b)

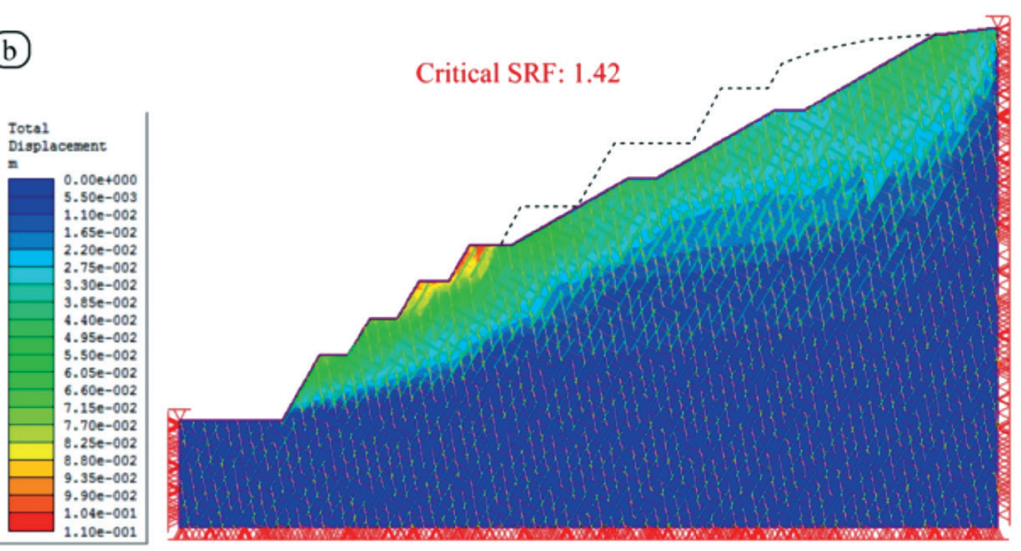

Şekil 9. Kaya şevinin (a) bulon uygulaması ve (b) yatıklaşlaştırması sonrasında duraylılık durumlarını gösteren sayısal analiz sonuçları.

Figure 9. Results of numerical analyses for the rock slope showing stability conditions after (a) bolting and (b) slope flattening.

c) Sayısal duraylılık analizi sonuçlarına göre kaya şevinde devrilme türü bir yenilme beklenilmektedir. Kaya şevinin duraylılı̆̆ının sağlanması için bulonlama yapılması veya şevin yatıklaştırılması önerilmektedir. İyileştirme yöntemlerinin performansları FEM tabanlı sayısal analiz yöntemiyle incelendiğinde bulonlama sonrası güvenlik sayısı 1.33 'e, şev yatıklaştırma işlemi sonrası ise 1.42 'ye çıkmaktadır. Önerilen yöntemlerden hangisinin uygulanacağına maliyet analizleri yapılarak karar verilmelidir.

d) Kaya şevlerinin duraylılığının araştırılmasında hem kaya kütlesinin hem de süreksizliklerin özelliklerini dikkate alan sayısal analizleri kullanmak daha gerçekçi sonuçların elde edilmesini sağlamaktadır. Dolayısıyla, duraylılık değerlendirmelerinde birden fazla yöntemi kullanarak sonuçları kontrol etmek, güvenilir şev tasarımı açısından önemlidir.

\section{TEŞEKKÜR}

Arazi çalışmalarının yürütülmesinde yardımcı olan Jeoloji Mühendisi Köksal AKIN'a, çalışmayı titizlikle değerlendiren hakemlere ve editöre teşekkür ederim. 


\section{KAYNAKLAR}

Aydan, Ö., Akagi, T., Kawamoto, T., 1993. The squeezing potential of rocks around tunnels; theory and prediction. Rock Mechanics and Rock Engineering, 26 (2), 137-163.

Barka, A., Sütçü Y. F., Gedik, İ., Tekin, T. F., Arel, E., Özdemir, M., Erkal, T., 1986. Sinop nükleer enerji santrali için jeolojik araştırmalar sonuç raporu, MTA, Rapor No: 7963, Ankara.

Barton, N., Bandis, S. C., 1990. Review of predictive capabilities of JRC-JCS model in engineering practice. Proceedings of the International Symposium on Rock Joints, Loen, Norway, 603610.

CANMET, 1977. Pit slope manual: supplement 5-1, plane shear analysis. Canada Centre for Mineral and Energy Technology Report, 16-77.

Deere, D. U., 1964. Technical description of rock cores for engineering purposed. Rock Mechanics and Rock Engineering, 1, 17-22.

Franklin, J. A., Broch, E., Walton, G., 1971. Logging the mechanical character of rock. Transactions of the Institution of Mining and Metallurgy, 80 (A), 1-9.

Güven, İ. H., 1993. Doğu Pontidlerin jeolojisi ve 1/250000 ölçekli komplikasyonu, MTA, Ankara.

Hoek. E., Bray, J. W., 1981. Rock Slope Engineering. Institution of Mining, Metallurgy, London, 358 p.

Hoek, E., Carranza-Torres, C., Corkum, B., 2002. Hoek-Brown failure criterion. Proceedings of the 5th North American Rock Mechanics Symposium and 17th Tunneling Association of Canada Conference, Toronto, Canada, 267-273.

Hoek, E., Diederichs, M. S., 2006. Empirical estimation of rock mass modulus. International
Journal of Rock Mechanics and Mining Science, 43, 203-215.

Hoek, E., Carter, T.G., Diederichs, M. S., 2013. Quantification of the Geological Strength Index chart. 47th US Rock Mechanics and Geomechanics Symposium, San Francisco, USA.

ISRM, 2007. The complete ISRM suggested methods for rock characterization, testing and monitoring: 1974-2006 (Editors: Ulusay and Hudson), International Society for Rock Mechanics, Kozan Ofset, Ankara, 628 p.

Mines Branch, 1972. Tentative design guide for mine waste embankments in Canada. Department of Energy, Mines and Resources, Canada, 200 p.

Palmström, A., 2005. Measurements of and Correlations Between Block Size and Rock Quality Designation (RQD), Tunnels and Underground Space Technology, 20, 362-377.

Priest, S. D., Hudson, J. A., 1976. Discontinuity spacing in rock. International Journal of Rock Mechanics and Mining Sciences and Geomechanics, Abstracts, 13, 135-148.

Rocscience, 2002. RocLab v1.0 rock mass strength analysis using the generalized Hoek-Brown failure criterion. Rocscience Inc., Toronto, Ontario, Canada.

Rocscience, 2011. Phase ${ }^{2}$ v8.0 2D finite element program for calculating stresses and estimating support around the underground excavations. Geomechanics Software and Research, Rocscience Inc., Toronto, Ontario, Canada.

Ulusay, R., Tuncay, E., Sonmez, H., Gokçeoglu, C., 2004. An attenuation relationship based on Turkish strong motion data and iso-acceleration map of Turkey. Engineering Geology, 74 (3-4), 265-291. 
